\title{
WPS4289
}

\author{
Policy Research Working Paper 4289
}

\section{Sensitivity of Cropping Patterns in Africa to Transient Climate Change}

\author{
Alexander Lotsch
}

The World Bank

Development Research Group

Sustainable Rural and Urban Development Team

July 2007 
Policy Research Working Paper 4289

\section{Abstract}

The detailed analysis of current cropping areas in Africa presented here reveals significant climate sensitivities of cropland density and distribution across a variety of agro-ecosystems. Based on empirical climate-cropland relationships, cropland density responds positively to increases in precipitation in semi-arid and arid zones of the sub-tropics and warmer temperatures in higher elevations. As a result, marginal increases in seasonal precipitation lead to denser cropping areas in arid and semi-arid regions. Warmer temperatures, on the other hand, tend to decrease the probability of cropping in most parts of Africa (the opposite is true for increases in rainfall and decreases in temperatures relative to current conditions).

Despite discrepancies and uncertainties in climate model output, the analysis suggests that cropland area

in Africa is likely to decrease significantly in response to transient changes in climate. The continent is expected to have lost on average 4.1 percent of its cropland by 2039 , and 18.4 percent is likely to have disappeared by the end of the century. In some regions of Africa the losses in cropland area are likely to occur at a much faster rate, with northern and eastern Africa losing up to 15 percent of their current cropland area within the next 30 years or so. Gains in cropland area in western and southern Africa due to projected increases in precipitation during the earlier portions of the century will be offset by losses later on. In conjunction with existing challenges in the agricultural sector in Africa, these findings demand sound policies to manage existing agricultural lands and the productivity of cropping systems.

This paper — a product of the Sustainable Rural and Urban Development Team, Development Research Group—is part of a larger effort in the group to mainstream climate change research. Copies of the paper are available free from the World Bank, 1818 H Street NW, Washington, DC 20433. Please contact Pauline Kokila, room MC3-446, telephone 202-4733716, fax 202-522-1151, email address pkokila@worldbank.org. Policy Research Working Papers are also posted on the Web at http://econ.worldbank.org. The authors may be contacted at alotsch@worldbank.org. July 2007. (27 pages)

The Policy Research Working Paper Series disseminates the findings of work in progress to encourage the exchange of ideas about development issues. An objective of the series is to get the findings out quickly, even if the presentations are less than fully polished. The papers carry the names of the authors and should be cited accordingly. The findings, interpretations, and conclusions expressed in this paper are entirely those of the authors. They do not necessarily represent the views of the International Bank for Reconstruction and Development/World Bank and its affiliated organizations, or those of the Executive Directors of the World Bank or the governments they represent. 


\title{
SENSITIVITY OF CROPPING PATTERNS IN AFRICA TO TRANSIENT CLIMATE CHANGE ${ }^{1}$
}

\author{
Alexander Lotsch $^{2}$
}

${ }^{1}$ An earlier version of this Working Paper was published as CEEPA Discussion Paper number 14.

2 Agriculture and Rural Development Department, The World Bank, Washington DC, e-mail: alotsch@,worldbank.org.

This paper was funded in part by the GEF and the World Bank. It is part of a larger study on the effect of climate change on agriculture in Africa, managed by the World Bank and coordinated by the Centre for Environmental Economics and Policy in Africa (CEEPA), University of Pretoria, South Africa. 



\section{TABLE OF CONTENTS}

$\begin{array}{ll}\text { Section } & \text { Page }\end{array}$

1 Introduction 4

2 Data on cropping patterns 4

3 Explaining variations in land use patterns 5

$4 \quad$ Sensitivity of cropping patterns to seasonal perturbations in climate 8

$5 \quad$ Changes in land use resulting from climate trends projected by climate 9 models

$6 \quad$ Conclusions and policy implications 12

References 14 


\section{SUMMARY}

Agriculture is an important pillar of economic development in Africa and many countries in the region face significant socio-economic and technological challenges to promote growth in rural areas. In addition, climate change has been recognized as an important factor that has the potential to threaten development efforts in the agricultural and rural sector in many African countries, in particular in regions with a high percentage of rainfed cropping systems.

The detailed analysis of current cropping areas in Africa presented here reveals significant climate sensitivities of cropland density and distribution across a variety of agro-ecosystems. Based on empirical climate-croplands relationships, cropland density responds positively to increases in precipitation in semi-arid and arid zones of the sub-tropics and warmer temperatures in higher elevations. As a result, marginal increases in seasonal precipitation lead to denser cropping areas in arid and semi-arid regions. Warmer temperatures, on the other hand, tend to decrease the probability of cropping in most parts of Africa (the opposite is true for increases in rainfall and decreases in temperatures relative to current conditions).

While current climate-cropland relationships allow the geographic delineation of temperature and precipitation sensitivities, projections of climate parameters derived from coupled Atmosphere-Ocean General Circulation Models (AOGCMs) provide a sound basis for assessing the impact of future climate. Despite discrepancies and uncertainties in climate model output, the analysis suggests that cropland area in Africa is likely to decrease significantly in response to transient changes in climate. The continent is expected to have lost on average $4.1 \%$ of its cropland by 2039 , and $18.4 \%$ is likely to have disappeared by the end of the century. In some regions of Africa the losses in cropland area are likely to occur at a much faster rate, with northern and eastern Africa losing up to $15 \%$ of their current cropland area within the next 30 years or so. Gains in cropland area in western and southern Africa due to projected increases in precipitation during the earlier portions of the century will be offset by losses later on. In conjunction with existing challenges in the agricultural sector in Africa, these findings demand sound policies to manage existing agricultural lands and the productivity of cropping systems. 


\section{Introduction}

In many African countries agriculture will remain an important sector for promoting growth, supporting rural livelihoods and reducing poverty for several decades to come (IFAD 2001). In addition to low productivity levels, degradation of natural resources and lack of investment in rural infrastructure, climate change represents a significant challenge for agro-ecosystems in the region (Rosenzweig \& Parry 1994). There is increasing consensus among experts that the impacts of human activity on the global climate system are already felt in many parts of the world and are likely to affect the most vulnerable regions and sectors in the near future (IPCC 2001). For the African region, an important question therefore is how projected trends in climate are going to affect agriculture and, by extension, food security, sustainable use of natural resources, and economic development. The work presented here investigates the sensitivity of current cropping patterns in Africa to seasonal perturbations in climate and assesses the potential impact of transient climate change suggested by climate model scenarios.

Since the emergence of agriculture farmers have developed techniques to overcome the biological and physical constraints that climate and land pose for the production of crops, including irrigation, land terracing and fertilization. Despite these agricultural management practices, crops remain ultimately dependent on ecological conditions, such as the intraseasonal distribution of precipitation and temperature, soil fertility and length of growing season. While cropping in boreal regions is limited by low temperatures and a short growing season, cropping in tropical and subtropical regions tends to be limited by inadequate moisture conditions and high temperatures (Cramer \& Solomon 1993). Recent work on the impacts of climate change suggests that countries in tropical latitudes will experience negative effects on economic development as a consequence of further warming and changes in precipitation patterns (Mendelsohn et al. 2000).

To assess climate change impacts on cropping patterns in Africa, this work (i) quantifies the extent of croplands across a variety of agro-ecosystems, (ii) relates current cropping patterns to climate, soil and terrain attributes through empirical models, and (iii) predicts how these patterns are likely to change based on the transient changes in climate projected by global Atmosphere-Ocean General Circulation Models (AOGCMs). This work is part of a wider effort to understand the economic effect of climate change on agriculture and the way farmers adapt in response to agro-ecological conditions (Dinar et al. 2006).

\section{Data on current cropping patterns in Africa}

To estimate the impact of climate change on cropland patterns across a variety of agroecological and climatic zones, geographically continuous representations of croplands, climate and other physical land properties were used. To do this, the continental land area was partitioned into grid cells of $.5^{\circ}$ latitude by $.5^{\circ}$ longitude (about 50-60 kilometer square grids in tropical and subtropical regions) and all variables described below were assimilated to the same data grid.

Because of the lack of sufficient, consistent and geographically coherent data on cropping systems for the whole of Africa, this analysis uses global land cover inventories derived from satellite observations in conjunction with ancillary statistical data on land use and agricultural 
activity. Satellite based estimates provide a spatially explicit and unbiased picture of the distribution of croplands and can be updated frequently at relatively low cost. However, alternative mapping approaches using different data and algorithms often result in different depictions of cropping patterns in terms of both location and density (Giri et al. 2005; Hannerz \& Lotsch 2006).

Due to these discrepancies, several sources of remote sensing-based land cover maps were used to control for the effect of their quality on cropland-climate models. These data sources include land cover data developed at Boston University (Friedl et al. 2002) based on the National Aeronautics and Space Administration (NASA) Moderate Imaging Spectroradiometer (MODIS) instrument, the Global Land Cover Facility (GLCF) data archive from the University of Maryland (Hansen et al. 2000), the 2000 Global Land Cover inventory (GLC2K) produced by the European Union's Joint Research Center (Mayaux et al. 2003), and the Global Land Cover Characterization (GLCC) created by the United States Geological Survey (Loveland et al. 1991).

Each of these sources provides categorical labels of land use (e.g. croplands, cropland mosaic, forest, shrublands) at the scale of one square kilometer. The GLCC data has the highest categorical detail with 197 land cover categories for the African continent, many of which capture agricultural land use. The information on agricultural land use provided by the GLCC data was used by the LandScan project at the Oak Ridge National Laboratory (ORNL) and International Food Policy Research Institute (IFPRI) as the basis for estimating agricultural extent at the landscape level (Dobson et al. 2000; Wood et al. 2000). Lastly, the Center for Sustainability and Global Environment (SAGE) at the University of Wisconsin inter-calibrated remote sensing based estimates of cropland extent from GLCC with available agricultural statistics at the national and sub-national level (Ramankutty \& Foley 1998). For this analysis, these six sources of land use data - MODIS, GLCF, GLC2K200, ORNL, IFPRI, and SAGE - were reprocessed using a consistent definition of land use and the aggregate extent and share of croplands was calculated for each grid cell.

The sub-regional breakdown of cropland extent and cropland share shown in Table 1 illustrates the discrepancies in estimates of cropland extent from different sources of land cover data and highlights the importance of accounting for the effect of these estimates in climate change impact analyses. For instance, the estimates of cropland extent for West Africa range from 1.52 million hectares (MODIS) to 12.20 million hectares (GLC2K) and from .78 million hectares (MODIS) to 10.77 million hectares (ORNL) for southern Africa. Similar disagreement is observed when assessing the sub-regional distribution of cropland share. While some approaches fail to account for sparsely cropped areas, others tend to identify crops reasonably well in mixed land use systems, but to overestimate the actual share of crops.

\section{Explaining variations in land use patterns}

For large geographic regions the suitability of land for cropping is largely determined by ecological and physical parameters (Ramankutty et al. 2002; Woodward \& Williams 1987). Thus, to explain current land use in Africa an empirical modeling approach is chosen that relates cropping patterns to a set of explanatory variables. For the purpose of this study, land use patterns are modeled using a set of such variables (seasonal climate patterns, soil and terrain properties), and it is assumed that socio-economic variables play a secondary role in 
determining the distribution of croplands at the spatial scale (continent) chosen for this analysis.

\subsection{The empirical cropland sensitivity model}

A logistic regression model was used to predict cropland fraction, which was transformed to a non-linear and bounded response variable using the logit transformation of the odds ratio:

$\log (Q)=f(K, T, S, P)+e$

where $\mathrm{Q}=\mathrm{p} /(1-\mathrm{p})$ is the odds ratio and $\mathrm{p}$ is the fraction (probability) of cropland in a $.5^{\circ}$ grid cell, $K$ is a vector of climate variables, $T$ is a vector of terrain variables, $S$ is a vector of soil variables, $P$ is population density and $e$ is an identically and independently distributed (iid) error term. To minimize any bias in the model, the spatial (cross-sectional) sample of predictor variables was limited to areas (grid cells) where a non-zero share of cropland is observed. This eliminates areas that are either characterized by unfavorable conditions for cropping (desert areas) or areas that are not accessible to develop cropping systems (e.g. tropical rainforest in the central Congo basin). In addition to linear terms for the independent variables, squared terms are included in the regression to provide more degrees of freedom in the functional relationship between cropland share and the predictor variables. The final regression equation is:

$\log (Q)=C_{0}+C_{1} K+C_{2} K^{2}+C_{3} T+C_{4} T^{2}+C_{5} S+C_{6} S^{2}+C_{7} P+C_{8} P^{2}+e$

where $C_{i}$ are vectors of coefficients corresponding to the respective predictor variables.

\subsection{Specification of model variables}

Mean annual conditions of climate provide a first-order approximation of land suitability for cropping, but intra-seasonal climate patterns play an equally critical role for crop cultivation and management. Climate is therefore empirically defined using a vector of seasonally adjusted climate variables that correspond to various stages of the cropping cycle. To do this, monthly climate observations were adjusted to reflect intra-annual changes in temperature and precipitation that correspond to the relative position of the sun throughout the calendar year at different latitudes. That is, the seasons are centered on the hottest (summer) and coolest (winter) months, which correspond to the highest and lowest solar position throughout the year, respectively. Similarly, spring (beginning of growing season) and fall (harvest) coincide with increasing and decreasing sun angle (equinox dates), respectively. Finally, temperature and precipitation observations were aggregated to three-month seasonal averages to minimize serial correlation in climate records. This process normalizes climate 
observations by accounting for different phasing of the growing cycle at different latitudes, which is critical for making inter-regional comparisons. The specific data sources used to parameterize the model variables are briefly described below.

Seasonal climate: The basis for the characterization of geographic and intra-annual (seasonal) climate patterns was a dataset of multi-decadal observations of temperature and precipitation made at meteorological stations throughout Africa. This data was preprocessed by the Climate Research Unit at the University of East Anglia (Mitchell \& Jones 2005). The time series recorded at each station were systematically screened for quality and consistency and also assimilated onto a mesh of $0.5^{\circ}$ grid cells. To characterize salient intra-annual climate variation at each location, precipitation and temperature observations were converted to longterm (1961-2000) monthly averages.

Growing period: The length of the growing season is a critical determinant of cropping systems, and captures the period during which ecological conditions permit plant growth (Woodward 1987). In addition to the amplitude of intra-seasonal climate variations derived from the long-term records, growing season length provides a simple index for delineating the cold and dry threshold dates during the growing season that cannot be resolved from monthly records. To estimate growing season length for each grid cell, time series of vegetation activity derived from multi-temporal satellite observations of vegetation greenness (Tucker et al. 2005) were used to determine the onset, peak and end of the growing period. Seasonal changes in the vigor of terrestrial vegetation reflect the combined effect of temperature, precipitation and day length on plant growth, and the resulting estimates of growing season length therefore provide a suitable quantity for defining the growing period of rainfed crops (Zhang et al 2004).

Soil and terrain: Land characteristics were derived from a global soil dataset (Global Soil Data Task 2000) that captures edaphic properties at relatively fine spatial scales $\left(\sim 10 \mathrm{~km}^{2}\right)$. Chemical properties of soils were characterized using the ratio of organic and non-organic compounds, which are indicative of soil fertility, and are derived from carbon and nitrogen concentrations in the soil ( $\mathrm{C}: \mathrm{N}$ ratio). Hydraulic properties are important for the moisture supply of crops and were defined using estimates of field capacity derived from textural soil properties. Similarly, thermal capacity plays an important role in controlling biological processes in the soil and root system of crops and reflects how well soils provide suitable conditions for crop growth. Lastly, a digital elevation model was used to estimate topographic land features (Verdin \& Greenlee 1996) such as slope angle.

Population patterns: Estimates of population densities derived from national and sub-national population statistics were used as an additional input variable to explain spatial patterns of cropland (CIESIN/CIAT 2004). 


\section{Sensitivity of cropping patterns to seasonal perturbations in climate}

Results for the regression coefficients based on the cropland sensitivity models capture the effect of the predictor variables on cropland share and are shown in Table 2 for each of the six cropland models (MODIS, GLCF, GLC2K, ORNL, SAGE, IFPRI). The coefficients indicate the change in the log of the odds ratio per unit change of the predictor variables ( $[10 \mathrm{~mm}]$ for precipitation and $\left[{ }^{\circ} \mathrm{C}\right]$ for temperature; refer to table caption for details). Model diagnostics are provided at the bottom of each column. Model fits $\left(R^{2}\right)$ range from .22 (GLCF) to .39 (SAGE) and the majority of coefficients are statistically significant $(\mathrm{p}<.05$, non-significant coefficients are indicated by $*$ ). Coefficients smaller than .001 (marginal effect $<0.1 \%$ ) are omitted for clarity.

To summarize these results, the marginal effect of each variable was evaluated by combining both linear and quadratic terms and calculating the slope (sensitivity) at the sample mean (Table 3 ). Also, $\log$ odds were converted to odds $(Q)$ for interpretability. Thus, values greater than one indicate a positive marginal effect and values smaller than 1 indicate a negative marginal effect. For example, an odds ratio coefficient of 1.05 indicates that the odds of having croplands at a given location increases by $5 \%$ for each unit increase in the predictor variable. The combined effect of temperature and precipitation across all seasons and soil variables is shown in italics, and the multi-model mean is shown is the last column.

The results show that, for current climate conditions, the cropland models predict a positive effect for precipitation $(1.048-1.233$, with the exception of GLC2K, .775) and a negative effect for temperature $(.812-.951)$ when compounding all seasonal coefficients. That is, increases/decreases in seasonal precipitation result in a higher/lower cropland share, whereas increases/decreases in temperature are associated with lower/higher cropland share.

Moreover, interesting patterns are revealed in the seasonal breakdown of climate effects. While increases in precipitation during spring, summer and fall tend to have a positive marginal effect, additional rainfall during winter is negative. This is intuitive, as moisture requirements are most critical during the crops' main growing season, but are less important during soil preparation and regeneration. Temperature coefficients, on the other hand, exhibit an opposing seasonal pattern, whereby warmer temperatures during the winter are positive, but higher temperatures during spring, summer and fall tend to decrease cropping. This is consonant with the notion that there is an optimum temperature for cropping systems, beyond which increases in temperature have adverse effects (i.e. a hill-shaped functional relationship). During the coldest season, however, warmer temperatures can have positive effects as they influence soil regenerative processes during the fallow period.

The marginal effects of the chemical, hydraulic and thermal properties of soils are consistently positive. That is, the ability of soils to retain water and store heat tends to be beneficial for crops and increases the likelihood of croplands. Similarly, higher soil fertility ( $\mathrm{C}: \mathrm{N}$ ratio) makes it more probable that land will be used for cropping. By extension, active management and preservation of soil properties is critical for maintaining cropland suitability.

The effect of changes in growing season length is very small (.999), which is not surprising as these effects are known to be most important in higher latitudes. Also, the marginal effect of topography is negative (.987), which indicates that steeper slopes tend to reduce the density of croplands. However, the magnitude of this effect is relatively small at the scale of this analysis (.5 grid cell). Lastly, population density tends to increase with cropland density 
and highlights the high degree of subsistence farming across the region. In more mechanized systems an inverse relationship has been observed in cross-sectional analysis (Mendelsohn et al. 2004), where cropping areas are characterized by lower population density.

To understand the impact of geographic changes in climate on cropping it is important to model the spatial distribution of croplands as accurately as possible. Figure 1 shows the spatial patterns of the residuals associated with each cropland model. While the marginal effects are similar in direction and magnitude for all six models (Table 3), the spatial patterns of predicted cropland share reflect the disagreement in the depiction of cropping patterns by the different land cover maps (Table 1). The areas of disagreement are mostly in regions that have sparse cropping patterns (semi-arid zones) or are characterized by mixtures of croplands and natural or forest vegetation at fine spatial scales. As a consequence, the models tend to underpredict croplands in areas with a high probability of cropping, such as eastern Africa, and to overpredict in areas with low probability.

Using these sensitivities, the seasonal and regional effects can be measured and mapped geographically. Spatial patterns of the combined seasonal effects on cropland share are shown in the left and right panels of Figure 2 for precipitation and temperature, respectively. This figure shows the marginal effect (expressed as changes in odds ratio) of precipitation and temperature (combining all seasons) and was calculated as the average across all six cropland models. Clearly, land use is most responsive to changes in climate in arid and semiarid regions in subtropical latitudes, where increases in precipitation have a positive effect on the suitability of land for cropping. The opposite is the case in humid tropical latitudes, where increases in seasonal rainfall have a negative effect, which arises from the negative long-term effect that high precipitation has on soil fertility through nutrient leaching and high organic turnover (Brady \& Weil 1996).

Increases in temperature, on the other hand, have largely negative marginal impacts throughout the African continent, with the exception of areas in southern and eastern Africa, where higher altitudes have a cooling effect on temperature. It is noteworthy that the marginal effect of changes in seasonal precipitation patterns is geographically more differentiated than the marginal effect of temperature, and shows that cropping systems in Africa are not expected to benefit from an additional rise in seasonal temperatures (assuming constant or decreasing levels of precipitation).

\section{Changes in land use resulting from climate trends projected by climate models}

The cropland model coefficients presented in the previous section are a measure of the sensitivity of land use to changes in the independent variables and quantify the impact of uniform (spatially averaged) and arbitrary changes in climate on croplands. However, perturbations in climate arising from increasing greenhouse gas concentrations in the atmosphere are unlikely to be uniform across seasons and space. This section therefore discusses the way spatially differentiated projections of future climate provided by an ensemble of seven coupled AOGCMs are expected to affect croplands in Africa. 


\subsection{Ensemble projections of climate}

The models used to evaluate the impact of climate change on cropland distributions in Africa for 2010-2099 are from (1) the Center for Climate Systems Research (CCSR) (Emori et al. 1999), (2) the Canadian Center for Climate Modeling and Analysis (CCC) (Boer, Flato \& Ramsden 2000), (3) the Goddard Fluid Dynamics Laboratory (GFDL) (Delworth et al. 2002), (4) Australia's Commonwealth Scientific and Industrial Research Organization (CSIRO) (Hirst et al. 1996), (5) the Hadley Center for Climate Prediction and Research (HCCPR) (Gordon et al. 2000), (6) the Max-Planck Institute for Meteorology (MPIM) (Roeckner et al. 1996), and (7) the National Center for Atmospheric Research (NCAR) (Washington et al. 2000). These models provide dynamic pathways of climate up to 2099 at a monthly time step and capture changes in the general patterns of atmospheric circulation as a result of increased greenhouse gases in the atmosphere. The model runs chosen for this analysis are based on the A2 emission scenario defined by the Intergovernmental Panel on Climate Change, which provides projections based on a very heterogeneous world with continuously increasing global population and regionally oriented economic growth that is relatively fragmented and slow (Nakicenovic \& Swart 2000).

Long-term mean conditions of future climate were evaluated for three distinct periods (20102039, 2040-69 and 2070-2099) and expressed as 30-year monthly means. The monthly predictions were seasonally adjusted in the same fashion as the historical 1961-2000 baseline record and resampled to the same grid resolution $\left(0.5^{\circ}\right)$. The resulting estimates were then used to predict changes in cropland share at the grid cell level.

For reference, changes in long-term seasonal precipitation and temperature for the 2010-2039 period are shown in Figure 3, and the respective agreement in the direction of change across seven AOGCMs is shown in Figure 4. The comparison shows that the models tend to agree on decreases in precipitation in the eastern and central part of the continent and a general increase in precipitation in subtropical latitudes (Figure 4). The largest increase in precipitation in these regions is projected for the summer and spring season (left hand panels in Figure 3), and projected decreases in precipitation are most significant in the equatorial coastal regions of the continent. For the winter and fall seasons, spatial patterns of precipitation change are less coherent.

Projected changes in surface temperature exhibit an equally non-uniform pattern, with the strongest temperature increase for the central and southern part of the continent during winter/spring and for the coastal areas in the southwestern and northern regions during summer/fall. The spatial patterns are less coherent in the central and eastern part of the continent throughout all seasons, and cooling is more likely in the high altitude regions of eastern and northeastern part of Africa (Figure 3). In general, the highest absolute changes in projected climate coincide with the regions of inter-model agreement and the seasons that exhibit a strong climate response, e.g. precipitation during the spring/summer and temperature during winter/spring (Figure 4).

Table 4 shows a breakdown of changes in mean annual precipitation and temperature for each 30 -year period and each climate model in each sub-region (North: $20-38^{\circ} \mathrm{N} / 10^{\circ} \mathrm{W}-40^{\circ} \mathrm{E}$; West: $5-20^{\circ} \mathrm{N} / 20^{\circ} \mathrm{W}-20^{\circ} \mathrm{E}$; East: $20^{\circ} \mathrm{N}-15^{\circ} \mathrm{S} / 30-50^{\circ} \mathrm{E}$; Central: $5^{\circ} \mathrm{N}-15^{\circ} \mathrm{S} / 8-30^{\circ} \mathrm{E}$; and South: $\left.15-35^{\circ} \mathrm{S} / 20-50^{\circ} \mathrm{E}\right)$. Changes in temperature are given in ${ }^{\circ} \mathrm{C}$ and changes in precipitation in \% relative to the 1961-2000 baseline. The table shows significant discrepancies across climate models. Specifically, while most models predict continuous warming across all regions for the entire time period, the CCC and NCAR model project a 
period of cooling across most regions, followed by warming towards the end of the century (as a result the ensemble projections shown exhibit a smaller warming rate during the first couple of decades). The projected changes in precipitation are equally inconsistent across models. While the GFDL and CCC models predict drier conditions across most regions, the remaining models show significant relative increase in precipitation and are regionally more differentiated. These uncertainties about the evolution of the climate in the coming decades necessitate the evaluation of climate change impacts on cropland patterns across a range of different climate scenarios and are further elaborated on in the next section.

\subsection{Projected changes in croplands}

The results presented above illustrate the discrepancies that exist across a variety of cropland models (CRMs), on the one hand, and across a range of climate models (AOGCMs), on the other. To characterize cropping pattern changes in Africa, this section evaluates the impact of climate change on croplands across the range of projections made by various models.

Table 5 shows relative changes in cropland area compared to current cropland patterns predicted by the ensemble average of seven AOGCMs. To do this, the unweighted mean of climate model projections was used to parameterize each of the six croplands models (column headers) and predict changes in cropland area for 2010-2039, 2040-2069 and 20702099 in each region and for the continent as a whole (rows). The right-most column shows the average impact across all CRMs. As far as the aggregate cropland area in Africa is concerned, different CRMs reveal a somewhat heterogeneous pattern, with some models showing increases and others showing decreases. However, towards the later periods of the century, most models agree on significant losses of cropland area across the continent. Considering the average change predicted by all CRMs, croplands are expected to decrease by $4.3 \%$ during the first 30 -year period, and by $9.4 \%$ and $18.3 \%$ by the middle and end of the century.

A more detailed look at the contribution of each sub-region to this overall pattern reveals that the highest relative loss is likely to occur in the northern and eastern part of the continent, whereas the western part (western Sahel) may experience increases in cropland share according to some CRMs. Again, while the earlier decades reveal heterogeneous patterns across the region, the later part of the period is characterized by losses of croplands in practically all sub-regions, with some cropland losses exceeding $30 \%$ in parts of the continent.

Table 6 shows a similar summary of regional cropland area changes for AOGCMs throughout the century. That is, the mean cropland density based on all six CRMs was used to evaluate changes in cropland area for each climate model across the various sub-regions. With the exception of the CCC model, all models show substantial losses in cropland area in the national aggregate and increasing cropland area losses towards the end of the century. Similar to the comparison of CRMs, the comparison of AOGCMs shows the strongest and most consistent loss of cropland in the northern and eastern part of the continent and gains of cropland area in western and southern Africa during the first period. However, this intermittent increase in cropland area is offset later in the century. Note that the last column in Table 6 is identical to the last column in Table 5 and shows the average change in cropland areas across all AOGCMs and CRMs. It is important to note that the positive relative effects 
in the West Africa and the Sahel remain rather insignificant due to a sparse distribution of current croplands and low population density.

To further illustrate the range of impacts across the region, Figure 5 shows a geographic representation of results based on the SAGE cropland model and the NCAR, CCSR and CCC climate model (only the 2010-2039 period is shown). For reference, the actual and modeled distributions of croplands based on the SAGE model are depicted in the left and center panels in the top row, respectively, and the spatial patterns arising from an ensemble prediction of climate models are shown in the right panel in the top row. Figure 5 shows that despite differences in the model projections from various AOGCMs, general patterns of cropland sensitivity can be discerned. That is, while subtropical latitudes may experience increases in croplands at the margins due to relative increases in precipitations, eastern and northern Africa are likely to experience the highest relative and absolute losses in cropland area early in the century.

\section{Conclusions and policy implications}

The objective of this analysis was to establish a quantitative relationship between land use in Africa and transient climate projections for the 21 st century. The analysis presented here shows that current cropping patterns in Africa can be predicted reasonably well using a reduced set of geophysical variables including long-term seasonal temperature and precipitation and soil characteristics. To do this, spatially continuous representations of cropland share, climate and soil data were used to estimate the location specific sensitivities of current cropping patterns to perturbations in seasonal climate. Based on these sensitivities, a probabilistic and spatially differentiated estimate of the impact of climate change was calculated.

The first part of the analysis showed that despite significant discrepancies in alternative depictions of cropland share at the sub-regional level, the seasonal effects of precipitation and temperature changes are relatively consistent across models. However, because of differences in the geographic distribution of croplands, spatial sensitivity patterns vary considerably at finer spatial scales (e.g. at below-national levels) from model to model. Also, the projections of AOGCMs used here to characterize future climate have largely global to regional scope and need to be interpreted with caution at the sub-regional and local scale. The results presented here therefore highlight the patterns that emerge from a synthesis of an ensemble of cropland model regressions and climate model projections.

Geographically distinct patterns of climate sensitivity characterize different agro-ecological zones. Specifically, changes in precipitation in semi-arid and humid region have opposing effects, but the majority of the African continent has a unidirectional sensitivity to changes in temperature (with exceptions in some parts of southern and eastern Africa). This is consonant with the notion that increases in temperature tend to have negative effects on agriculture in tropical latitudes, and changes in precipitation largely affect the tail ends of precipitation regimes. It is important to note, however, that this analysis is concerned only with the allocation of land to cropping and does not consider climate impacts on crop yield and agricultural productivity.

While the first part of the analysis estimates the effect of uniform (and arbitrary) changes of climate across the region, the second part assesses the impact of cropland changes arising 
from spatially and seasonally differentiated changes in climate as projected by AOGCMs. Again, while there is a relatively high degree of disagreement among models on the direction and magnitude of climate change, some salient patterns emerge from a systematic comparison of model projections. East Africa is expected to experience the highest absolute loss in cropland share due to a relatively high density of croplands today, whereas less densely cultivated areas will remain characterized by sparse cropping patterns despite positive changes at the margins. In general, the relative impact across the continent is highly differentiated and most pronounced in the tropical latitudes. Subtropical regions experience the least relative change due to positive perturbations in precipitation and temperature, respectively. Despite uncertainties in these estimates, the results make it clear that policy interventions in regard to land management, food policy, markets or poverty, intended to mitigate the impacts of climate change on agro-ecosystems, need to be tailored to each subregion, and that climate change needs to be considered when making long-term investments in agricultural infrastructure such as irrigation or the development of markets.

It is important to note that this analysis addresses only the impacts of changes in long-term average conditions of climate. However, there is a large body of evidence that shows that inter-annual variability in climate plays an important role for farmers' risk management and livelihood strategies, crop choices and safety nets. In particular, shock-like events such as droughts, floods or storms can have detrimental effects on farmers' welfare. Based on first order climate mechanisms, however, it is conceivable that patterns associated with these extreme events are likely to become more frequent with climate change (IPCC 2001) and may outweigh the effects of gradual changes in mean climate.

Ricardian analyses for Africa (Kurukulasuriya \& Mendelsohn, 2006) suggest that agricultural productivity exhibits a negative or a U-shaped relationship with cropland density. That is, the marginal effect of increasing cropland does not result in higher land productivity in lowdensity systems, whereas in areas of higher cropping probability the effect is small or slightly positive. In other words, current land use is a reflection of cropping systems having adapted to normal conditions in the natural environment. Expansion of croplands as a result of more favorable climate is a meaningful policy only in productive agro-ecosystems, but will perpetuate low agricultural productivity and, by extension, poverty (Mendelsohn et al., 2004) in marginal cropping areas. Conversely, in productive agro-ecosystems trends towards less favorable climate can be compensated for to some extent by further cropland expansion. However, this policy raises issues of the opportunity costs associated with converting from non-cropping land uses (urban, forest, land conservation) to agriculture.

The results suggest significant changes of cropping patterns across the region, which are likely to have implications for food security, agricultural markets and trade. Population trends projected for Africa (United Nations 2004) are likely to exacerbate demand for crops unless increases in agricultural productivity can compensate for the loss of cultivable land. The analysis also shows that measurable changes in cropping patterns are likely to occur within the next several decades, which stresses the importance of institutions and land use policies in identifying and managing the impacts of climate change on agro-ecosystems in response to changes in climate. An important aspect of this is the creation of a system of incentives to facilitate the adaptation of agro-ecosystems to new conditions. 


\section{REFERENCES}

Boer G, Flato G \& Ramsden D. 2000. A transient climate change simulation with greenhouse gas and aerosol forcing: projected climate for the 21st century. Climate Dynamics 16 $427-450$.

Brady NC \& Weil RR, 1996. The nature and properties of soils. New Jersey: Prentice Hall.

CIESIN/CIAT, 2004, Gridded Population of the World (GPW), Version 3. Center for International Earth Science Information Network \& Centro Internacional de Agricultura Tropical, Palisades NY, CIESIN Columbia University. http://sedac.ciesin.columbia.edu/gpw

Cramer WP \& Solomon AM, 1993. Climate classification and future global redistribution of agricultural land. Climate Research 3: 97-110.

Delworth TL et al., 2002. Review of simulations of climate variability and change with the GFDL R30 coupled climate model. Climate Dynamics 19, 555-574.

Dinar A, Hassan R, Kurukulasuriya P, Benhin J \& Mendelsohn R, 2006. The policy nexus between agriculture and climate change in Africa. A synthesis of the investigation under the GEF / WB Project, Regional Climate, Water and Agriculture: Impacts on and Adaptation of Agro-ecological Systems in Africa. CEEPA Discussion Paper No 39, Centre for Environmental Economics and Policy in Africa, University of Pretoria.

Dobson JE, Bright EA, Coleman PR, Durfee RC \& Worley BA, 2000. LandScan: A global population database for estimating populations at risk. Photogrammetric Engineering \& Remote Sensing 66: 849-857.

Emori S, Nozawa T, Abe-Ouchi A, Namaguti A \& Kimoto M, 1999. Coupled oceanatmosphere model experiments of future climate change with an explicit representation of sulfate aerosol scattering. Journal of the Meteorological Society of Japan 77: 1299-1307.

Friedl MA et al., 2002. Global land cover from MODIS: Algorithms and early results. Remote Sensing of Environment, 83: 287-302.

Giri C, Zhu Z \& Reed B. 2005. A comparative analysis of the Global Land Cover 2000 and MODIS land cover data sets. Remote Sensing of Environment 94: 123-132. 2005.

Global Soil Data Task, 2000. Global Soil Data Products CD-ROM (IGBP-DIS). International Geosphere-Biosphere Program - Data and Information Services. ORNL Distributed Active Archive Center, Oak Ridge National Laboratory, Oak Ridge, Tennessee, USA. http://www.daac.ornl.gov/

Gordon C et al., 2000. The simulation of SST, sea ice extents, and ocean heat transports in a version of the Hadley Centre coupled model without flux adjustments. Climate Dynamics 16: 147-168.

Hannerz F \& Lotsch A, 2006 (submitted). Assessment of land use inventories for Africa. Remote Sensing of Environment. 
Hansen M, Defries R, Townshend JRG \& Sohlberg R, 2000. Global land cover classification at $1 \mathrm{~km}$ resolution using a decision tree classifier. International Journal of Remote Sensing 21: 1331-1365.

Hirst AC, Gordon HB \& O'Farrell SP, 1996. Global warming in a coupled climate model including oceanic eddy-induced advection. Geophysical Research Letters 23: 33613364.

IFAD (International Fund for Agricultural Development), 2001, Rural Poverty Report 2000: The challenge of ending rural poverty. New York: Oxford University Press.

IPCC (Intergovernmental Panel on Climate Change), 2001, Climate Change 2001: The Scientific Basis. New York: Cambridge University Press.

Kurukulasuriya P \& Mendelsohn R, 2006. A Ricardian analysis of the impact of climate change on African cropland. CEEPA Discussion Paper No. 8, Centre for Environmental Economics and Policy in Africa, University of Pretoria.

Loveland T, Merchant J, Ohlen D \& Brown J, 1991. Development of a land cover characteristics database for the conterminous US. Photogrammetric Engineering \& Remote Sensing 57(11): 1453-1463.

Mayaux P et al., 2003. A land cover map of Africa. European Commission Joint Research Centre, Ispra, Italy, Report No. EUR 20665 EN.

Mendelsohn R, Basist A, Kurukulasuriya P \& Dinar A, 2006. Climate and rural income. Climatic Change May, Pages 1-18, DOI 10.1007/s10584-005-9010-5 http://dx.doi.org/10.1007/s10584-005-9010-5

Mendelsohn R, Morrison W, Schlesinger M \& Adronova N, 2000. Country-specific market impacts from climate change. Climatic Change 45: 553-569.

Mitchell TD \& Jones PD, 2005. An improved method of constructing a database of monthly climate observations and associated high-resolution grids. International Journal of Climatology 25:693-712.

Nakicenovic N \& Swart R, 2000. Emissions Scenarios. Special Report of the Intergovernmental Panel on Climate Change, Cambridge, UK: Cambridge University Press.

Ramankutty N \& Foley JA, 1998. Characterizing patterns of global land use: An analysis of global croplands data. Global Biogeochemical Cycles 12: 667-685.

Ramankutty N, Foley JA, Norman J \& McSweeney, K, 2002.The global distribution of cultivable lands: Current patterns and sensitivity to possible climate change. Global Ecology \& Biogeography 11: 377-392.

Roeckner E et al., 1996, The atmospheric general circulation model ECHAM-4: Model description and simulation of present-day climate, Max-Planck Institute for Meteorology, Hamburg, Report No. 218. 
Rosenzweig C \& Parry M. 1994. Potential impact of climate change on world food supply. Nature 367: 133-138.

Tucker CJ et al., 2005 (in press). An extended AVHRR 8-km NDVI data set compatible with MODIS and SPOT vegetation NDVI data. International Journal of Remote Sensing.

United Nations 2004, World Population to 2300, United Nations, New York.

Verdin KL \& Greenlee SK, 1996. Development of continental scale digital elevation models and extraction of hydrographic features. Proceedings of Third International Conference/Workshop on Integrating GIS and Environmental Modeling. 1-21. National Center for Geographic Information and Analysis, Santa Barbara, California.

Washington WM et al., 2000. Parallel climate model (PCM) control and transient simulations. Climate Dynamics 16: 755-774.

Wood S, Sebastian K \& Scherr S, 2000. Pilot Analysis of Global Ecosystems: Agrosystems, World Resources Institute and International Food Policy Research Institute, Washington DC.

Woodward FI, 1987. Climate and plant distribution. London: Cambridge University Press.

Woodward FI \& Williams BG, 1987. Climate and plant distribution at global and local scales. Vegetatio 69: 189-197.

Zhang X, Friedl MA, Schaaf CB \& Strahler AH, 2004. Climate controls on vegetation phenological patterns in northern mid- and high latitudes inferred from MODIS data. Global Change Biology 10: 1133-1145. 


\section{Table 1: Cropland area and share for sub-regions in Africa}

Cropland extent (in million ha) and share (in percent) are provided for each land use map (columns). Average cropland share is shown in italics below the cropland extent and was calculated as the area-weighted mean cropland share across all grid cells in the region. A sub-regional breakdown of cropland share and extent is shown in rows for northern $\left(20-38^{\circ} \mathrm{N}, 10^{\circ} \mathrm{W}-40^{\circ} \mathrm{E}\right)$, western $\left(5-20^{\circ} \mathrm{N}, 20^{\circ} \mathrm{W}-20^{\circ} \mathrm{E}\right)$, eastern $\left(20^{\circ} \mathrm{N}-15^{\circ} \mathrm{S}, 30-\right.$ $\left.50^{\circ} \mathrm{E}\right)$, central $\left(5^{\circ} \mathrm{N}-15^{\circ} \mathrm{S}, 8-30^{\circ} \mathrm{E}\right)$, and southern $\left(15-35^{\circ} \mathrm{S}, 20-50^{\circ} \mathrm{E}\right)$ Africa. Sub-regional averages across all land use maps are provided in the last column. The various land cover maps exhibit substantial differences in their sub-regional depiction of croplands. MODIS and GLCF tend to provide the lowest estimates, whereas GLC2K and ORNL tend to show the highest values.

\section{Cropland area [million ha]}

\section{Average cropland density [\%]}

\begin{tabular}{|c|c|c|c|c|c|c|c|c|c|}
\hline & MC & $D I S$ & & $C F$ & $G L C 2 K$ & ORNL & $S A G E$ & IFPRI & Mean \\
\hline \multirow{2}{*}{ North } & 0.78 & & 3.05 & & 4.59 & 10.77 & 4.11 & 5.86 & 4.86 \\
\hline & & $1.6 \%$ & & $6.5 \%$ & $8.0 \%$ & $21.4 \%$ & $8.2 \%$ & $12.0 \%$ & $9.6 \%$ \\
\hline \multirow{2}{*}{ West } & 1.52 & & 3.43 & & 12.20 & 7.00 & 2.85 & 3.89 & 5.15 \\
\hline & & $3.4 \%$ & & $5.0 \%$ & $18.4 \%$ & $10.4 \%$ & $5.4 \%$ & $7.0 \%$ & $8.3 \%$ \\
\hline \multirow{2}{*}{ East } & 3.14 & & 3.51 & & 12.16 & 9.70 & 6.10 & 7.68 & 7.04 \\
\hline & & $3.8 \%$ & & $4.7 \%$ & $15.0 \%$ & $12.0 \%$ & $7.6 \%$ & $9.4 \%$ & $8.8 \%$ \\
\hline \multirow{2}{*}{ Central } & 0.28 & & 1.21 & & 0.49 & 4.21 & 2.17 & 3.19 & 1.93 \\
\hline & & $0.5 \%$ & & $2.5 \%$ & $0.9 \%$ & $9.3 \%$ & $4.3 \%$ & $6.2 \%$ & $4.0 \%$ \\
\hline \multirow{2}{*}{ South } & 0.78 & & 3.05 & & 4.59 & 10.77 & 4.11 & 5.86 & 4.86 \\
\hline & & $1.6 \%$ & & $6.5 \%$ & $8.0 \%$ & $21.4 \%$ & $8.2 \%$ & $12.0 \%$ & $9.6 \%$ \\
\hline
\end{tabular}


Table 2: Cropland model regression results

Regression coefficients for cropland models SAGE, GLCF, MODIS, GLC2K, ORNL, IFPRI are based on a logistic regression model. Non-significant $(\mathrm{p}>0.05)$ coefficients are marked by* and confidence intervals are shown below each coefficient. Variables with marginal effects smaller than .1\% (.001) are omitted for clarity (e.g. squared terms for precipitation, soil and terrain properties). Regression diagnostics are provided in the bottom rows of each column. Independent variables are seasonal precipitation $\left(\mathrm{P}_{\mathrm{i}}\right)$ and temperature $\left(\mathrm{T}_{\mathrm{i}}\right)$, soil properties (field capacity, thermal capacity and $\mathrm{C}: \mathrm{N}$ ratio), growing season length, slope angle and population density. Bottom portion of the table shows coefficients associated with squared terms.

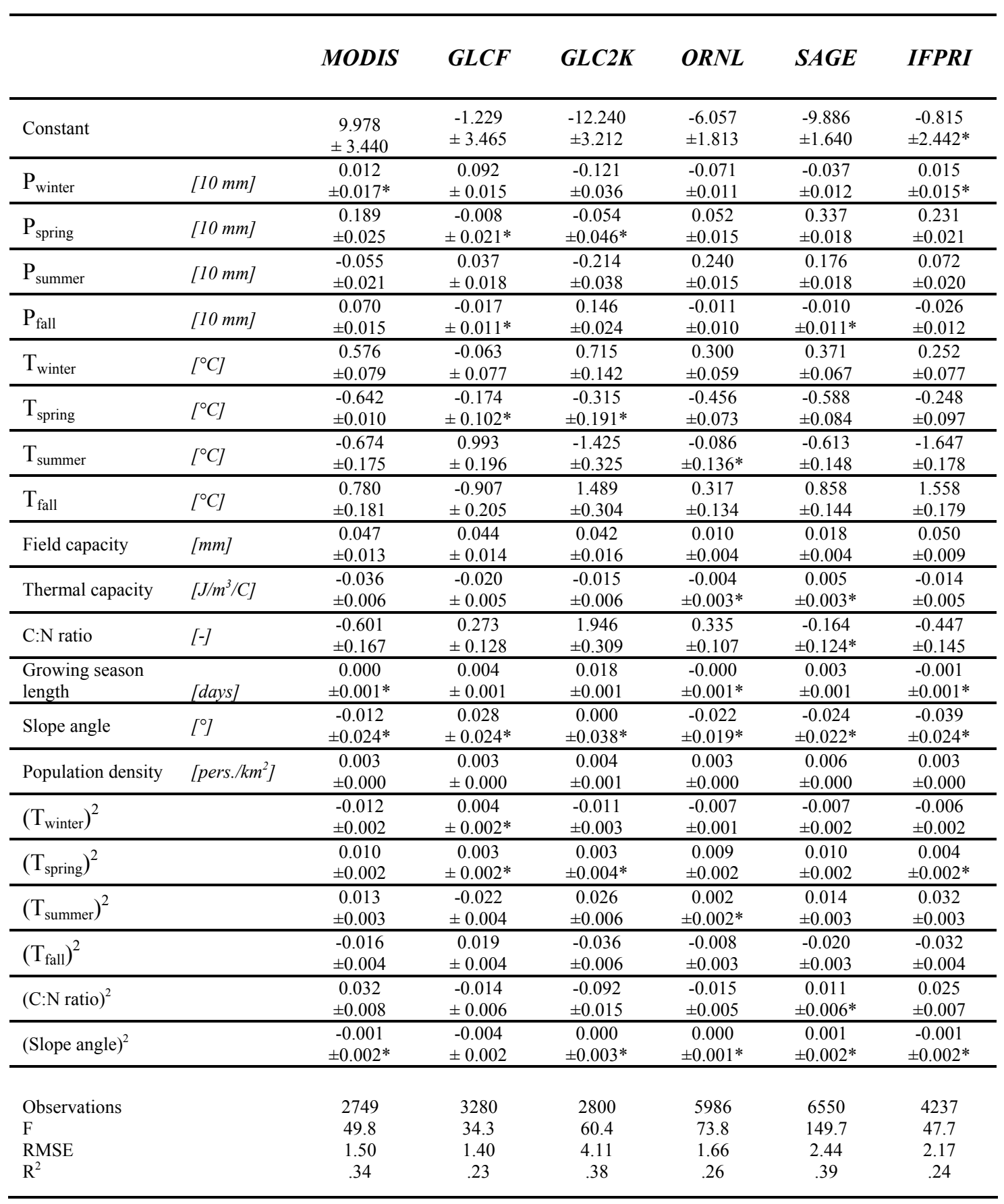


Table 3: Marginal effect of model variables of cropland share

Marginal effect/odds ratio were evaluated at sample mean for all six cropland models/columns combining linear and squared terms. Compounded effects across all seasons and soil properties are shown in italics. Values greater/smaller than 1 indicate positive/negative marginal effects (i.e. percent changes in odds ratio of cropland share). The last column shows multi-model average. For units refer to Table 2.

MODIS GLCF GLC2K ORNL SAGE IFPRI Ensemble

\section{Precipitation}

\begin{tabular}{rrrrrrrr}
\hline Winter & 0.987 & 1.036 & 0.859 & 0.942 & 0.937 & 0.991 & $\mathbf{0 . 9 5 9}$ \\
Spring & 1.109 & 0.976 & 0.929 & 0.995 & 1.183 & 1.106 & $\mathbf{1 . 0 5 0}$ \\
Summer & 0.954 & 1.033 & 0.894 & 1.114 & 1.092 & 1.024 & $\mathbf{1 . 0 1 9}$ \\
Fall & 1.042 & 1.010 & 1.086 & 1.003 & 1.019 & 1.001 & $\mathbf{1 . 0 2 7}$ \\
\hline Combined seasons & 1.088 & 1.055 & 0.775 & 1.048 & 1.233 & 1.123 & $\mathbf{1 . 0 5 4}$
\end{tabular}

\begin{tabular}{rrrrrrrrr} 
Temperature \\
\hline Winter & 1.155 & 1.089 & 1.278 & 1.029 & 1.109 & 1.023 & $\mathbf{1 . 1 1 4}$ \\
Spring & 0.786 & 0.965 & 0.851 & 0.925 & 0.833 & 0.901 & $\mathbf{0 . 8 7 7}$ \\
Summer & 0.986 & 0.888 & 0.947 & 1.040 & 1.108 & 0.935 & $\mathbf{0 . 9 8 4}$ \\
Fall & 1.063 & 0.976 & 0.788 & 0.941 & 0.894 & 1.090 & $\mathbf{0 . 9 5 9}$ \\
\hline Combined seasons & 0.951 & 0.911 & 0.812 & 0.932 & 0.916 & 0.939 & $\mathbf{0 . 9 1 0}$
\end{tabular}

\begin{tabular}{rrrrrrrr} 
Soils \\
\hline Field capacity & 1.005 & 1.002 & 1.004 & 1.004 & 1.007 & 1.005 & $\mathbf{1 . 0 0 5}$ \\
Thermal capacity & 1.003 & 1.002 & 1.002 & 1.002 & 1.003 & 1.001 & $\mathbf{1 . 0 0 2}$ \\
C:N ratio & 0.998 & 1.000 & 1.224 & 1.053 & 1.050 & 1.027 & $\mathbf{1 . 0 5 9}$ \\
\hline Combined soils & 1.006 & 1.004 & 1.232 & 1.060 & 1.060 & 1.034 & $\mathbf{1 . 0 6 6}$
\end{tabular}

\begin{tabular}{rlllllll}
\multicolumn{10}{l}{ Other variables } \\
\hline Growing season length & 0.999 & 0.998 & 0.998 & 0.999 & 0.999 & 0.999 & $\mathbf{0 . 9 9 9}$ \\
Terrain slope & 0.986 & 1.018 & 1.000 & 0.978 & 0.979 & 0.960 & $\mathbf{0 . 9 8 7}$ \\
Population & 1.003 & 1.003 & 1.004 & 1.003 & 1.006 & 1.003 & $\mathbf{1 . 0 0 4}$ \\
\hline
\end{tabular}


Table 4: Climate change for African sub-regions projected by general circulation models

Sub-regional breakdown of changes in annual mean temperature $\left(\Delta \mathrm{T}\right.$ in $\left.{ }^{\circ} \mathrm{C}\right)$ and precipitation $(\Delta \mathrm{P}$ in $\%)$ is based on projections by seven AOGCMs for three 30-year periods during the 21st century (top: 2010-2039, center: 2040-2069, bottom: 2070-2099). Note that CCC and NCAR predict cooling in most regions and only exhibit warming later in the century. Similarly, NCAR and CSIRO predict substantially higher rates of change for precipitation than other models.

\begin{tabular}{|c|c|c|c|c|c|c|c|c|c|c|c|c|c|c|}
\hline & \multicolumn{2}{|c|}{ CCSR } & \multicolumn{2}{|c|}{$C C C$} & \multicolumn{2}{|c|}{ HCCPR } & \multicolumn{2}{|c|}{ CSIRO } & \multicolumn{2}{|c|}{ MPIM } & \multicolumn{2}{|c|}{ GFDL } & \multicolumn{2}{|c|}{$N C A R$} \\
\hline & $\Delta \mathrm{T}$ & $\Delta \mathrm{P}$ & $\Delta \mathrm{T}$ & $\Delta \mathrm{P}$ & $\Delta \mathrm{T}$ & $\Delta \mathrm{P}$ & $\Delta \mathrm{T}$ & $\Delta \mathrm{P}$ & $\Delta \mathrm{T}$ & $\Delta \mathrm{P}$ & $\Delta \mathrm{T}$ & $\Delta \mathrm{P}$ & $\Delta \mathrm{T}$ & $\Delta \mathrm{P}$ \\
\hline & {$\left[{ }^{\circ} \mathrm{C}\right]$} & {$[\%]$} & {$\left[{ }^{\circ} \mathrm{C}\right]$} & {$[\%]$} & {$\left[{ }^{\circ} \mathrm{C}\right]$} & {$[\%]$} & {$\left[{ }^{\circ} \mathrm{C}\right]$} & {$[\%]$} & {$\left[{ }^{\circ} \mathrm{C}\right]$} & {$[\%]$} & {$\left[{ }^{\circ} \mathrm{C}\right]$} & {$[\%]$} & {$\left[{ }^{\circ} \mathrm{C}\right]$} & {$[\%]$} \\
\hline \multicolumn{15}{|c|}{$2010-2039$} \\
\hline North & 5.0 & 50 & -2.3 & -36 & 0.3 & 22 & 2.5 & 463 & 2.4 & 68 & 1.9 & -2 & -3.8 & 366 \\
\hline West & 1.2 & -41 & -2.9 & -14 & 1.2 & -19 & 0.6 & 280 & 1.1 & -12 & 1.2 & -55 & -3.5 & 90 \\
\hline East & 1.4 & 16 & -2.6 & -53 & 1.5 & 63 & 2.1 & 224 & 2.5 & 27 & 1.0 & -44 & -1.9 & 1964 \\
\hline Central & 1.4 & 163 & -1.1 & 24 & 1.6 & -21 & 0.4 & 154 & 1.9 & 25 & 2.2 & -11 & -0.9 & -26 \\
\hline South & 1.6 & 99 & -0.1 & -19 & 1.9 & 34 & 2.5 & 125 & 3.5 & 3 & 1.8 & -18 & -0.4 & -3 \\
\hline
\end{tabular}

2040-2069

\begin{tabular}{rccccccccccccccccccc}
\hline North & 7.2 & 85 & -0.9 & -33 & 1.7 & 41 & 4.0 & 634 & 3.8 & 77 & 2.9 & -5 & -3.0 & 469 \\
West & 2.1 & -41 & -1.8 & -15 & 2.6 & -25 & 1.7 & 355 & 2.3 & -16 & 2.2 & -55 & -2.8 & 38 \\
East & 2.2 & 6 & -1.6 & -52 & 2.8 & 63 & 3.1 & 394 & 3.6 & 18 & 1.9 & -44 & -1.2 & 1687 \\
Central & 2.6 & 198 & -0.1 & 28 & 3.0 & -20 & 1.2 & 72 & 3.3 & 48 & 3.1 & -13 & -0.3 & -27 \\
South & 2.8 & 107 & 1.0 & -16 & 3.2 & 70 & 3.3 & 150 & 4.8 & 19 & 2.9 & -15 & 0.3 & 3
\end{tabular}

2070-2099

\begin{tabular}{rcccccccccccccc}
\hline North & 10.2 & 128 & 0.8 & -31 & 3.7 & 92 & 6.0 & 805 & 5.8 & 146 & 4.2 & -12 & -1.7 & 1132 \\
West & 4.8 & -35 & 0.3 & -13 & 4.4 & -4 & 3.5 & 561 & 4.4 & 12 & 3.6 & -57 & -1.8 & 112 \\
East & 4.7 & 23 & 0.0 & -49 & 4.5 & 74 & 4.6 & 274 & 5.4 & 28 & 3.2 & -42 & -0.3 & 2153 \\
Central & 5.3 & 296 & 1.7 & 37 & 4.8 & -15 & 2.5 & 170 & 5.1 & 120 & 4.4 & -15 & 0.5 & -26 \\
South & 4.9 & 182 & 2.9 & -5 & 4.9 & 98 & 4.8 & 374 & 6.6 & 50 & 4.2 & -14 & 1.2 & 4 \\
& & & & & & & & & & & & & &
\end{tabular}


Table 5: Cropland area changes for different cropland models

Changes in cropland area (percent change relative to current extent) based on ensemble mean projections from 7 AOGCMs for 2010-2039 (top section), 2040-2069 (center section) and 2070-2099 (bottom section). Each section shows changes for the entire continent (italics) and for 5 sub-regions (see Table 1 for definitions). Columns show breakdown by cropland model (last column shows average across all models).

\begin{tabular}{|c|c|c|c|c|c|c|c|}
\hline & MODIS & $G L C F$ & $G L C 2 K$ & ORNL & $S A G E$ & IFPRI & Mean \\
\hline \multicolumn{8}{|c|}{ 2010-2039 } \\
\hline Africa & -11.2 & 2.1 & -28.3 & 4.8 & 16.8 & -9.7 & -4.3 \\
\hline North & 1.1 & -23.9 & -9.2 & -12.8 & -17.2 & -12.2 & -12.4 \\
\hline West & -11.0 & 15.3 & -26.3 & 31.0 & 61.7 & 5.3 & 12.7 \\
\hline East & -28.1 & -9.5 & -39.1 & -10.6 & 14.4 & -16.7 & -14.9 \\
\hline Central & -42.8 & 24.8 & 54.9 & -16.3 & 5.7 & -39.5 & -2.2 \\
\hline South & 0.2 & -8.8 & -7.0 & 6.2 & 25.2 & 0.9 & 2.8 \\
\hline
\end{tabular}

2040-2069

\begin{tabular}{rrrrrrrrr}
\hline \multicolumn{1}{l}{ Africa } & -16.2 & -3.3 & -37.0 & -0.2 & 12.3 & -12.1 & $\mathbf{- 9 . 4}$ \\
North & -3.4 & -30.5 & -22.5 & -20.2 & -27.1 & -16.8 & $\mathbf{- 2 0 . 1}$ \\
West & -17.4 & 3.5 & -35.8 & 21.3 & 66.3 & 13.1 & $\mathbf{8 . 5}$ \\
East & -33.4 & -11.4 & -48.5 & -13.3 & 13.0 & -19.3 & $\mathbf{- 1 8 . 8}$ \\
Central & -48.4 & 32.9 & 18.0 & -22.3 & -3.7 & -45.6 & $\mathbf{- 1 1 . 5}$ \\
South & -1.2 & -15.6 & -8.0 & 4.8 & 20.3 & -3.4 & $\mathbf{- 0 . 5}$ \\
\hline
\end{tabular}

2070-2099

\begin{tabular}{rrrrrrrrr}
\hline \multicolumn{1}{l}{ Africa } & -25.3 & -8.9 & -50.2 & -10.0 & 0.3 & -16.0 & $-\mathbf{1 8 . 3}$ \\
North & -13.0 & -37.2 & -41.8 & -33.5 & -41.7 & -20.8 & $\mathbf{- 3 1 . 3}$ \\
West & -25.5 & -7.2 & -49.2 & 5.1 & 73.3 & 26.5 & $\mathbf{3 . 8}$ \\
East & -43.2 & -15.9 & -62.1 & -24.6 & -7.1 & -29.9 & $\mathbf{- 3 0 . 4}$ \\
Central & -55.8 & 54.5 & -23.8 & -31.4 & -15.6 & -53.4 & $\mathbf{- 2 0 . 9}$ \\
South & -5.8 & -25.2 & -16.4 & 4.3 & 17.1 & -7.2 & $\mathbf{- 5 . 6}$ \\
\hline
\end{tabular}


Changes in cropland area (percent change relative to current extent) based on mean distribution of cropland area defined by 6 cropland models for 2010-2039 (top section), 2040-2069 (center section) and 2070-2099 (bottom section). Each section shows changes for the entire continent (italics) and for 5 sub-regions (see Table 1 for definitions). Columns show breakdown by AOGCM (last column shows average across all models).

\begin{tabular}{|c|c|c|c|c|c|c|c|c|}
\hline & CCSR & $C C C$ & HCCPR & CSIRO & MPIM & GFDL & $N C A R$ & Mean \\
\hline \multicolumn{9}{|c|}{$2010-2039$} \\
\hline Africa & -11.1 & 22.9 & -14.6 & -11.5 & -7.6 & -5.3 & -2.6 & -4.3 \\
\hline North & -35.8 & 28.7 & -6.0 & -19.8 & -4.0 & -42.7 & -7.1 & -12.4 \\
\hline West & 12.6 & 36.2 & -11.6 & -8.0 & 9.7 & 29.1 & 20.7 & 12.7 \\
\hline East & -19.3 & 18.7 & -21.7 & -23.4 & -29.9 & -4.6 & -24.4 & -14.9 \\
\hline Central & 36.5 & 32.2 & -41.5 & 37.9 & 6.5 & -44.0 & -43.1 & -2.2 \\
\hline South & -6.1 & -4.4 & -5.6 & 1.5 & 10.3 & -1.0 & 24.6 & 2.8 \\
\hline
\end{tabular}

\begin{tabular}{|c|c|c|c|c|c|c|c|c|}
\hline \multicolumn{9}{|c|}{$2040-2069$} \\
\hline Africa & -13.9 & 13.7 & -21.0 & -17.9 & -15.3 & -5.9 & -5.7 & -9.4 \\
\hline North & -50.6 & 13.3 & -13.3 & -24.6 & -12.7 & -44.1 & -8.6 & -20.1 \\
\hline West & 39.8 & 20.3 & -19.5 & -21.0 & 7.1 & 20.8 & 12.0 & 8.5 \\
\hline East & -22.5 & 12.4 & -29.5 & -27.1 & -39.5 & 1.3 & -26.8 & -18.8 \\
\hline Central & 6.8 & 22.4 & -44.5 & 23.0 & -0.2 & -45.4 & -42.6 & -11.5 \\
\hline South & -10.6 & -4.6 & -11.1 & -1.8 & 3.3 & -2.6 & 23.8 & -0.5 \\
\hline
\end{tabular}

2070-2099

\begin{tabular}{|c|c|c|c|c|c|c|c|c|}
\hline Africa & -13.9 & -3.9 & -32.3 & -29.8 & -23.5 & -12.5 & -12.5 & -18.3 \\
\hline North & -61.2 & -4.5 & -28.7 & -36.6 & -25.8 & -49.6 & -13.0 & -31.3 \\
\hline West & 79.5 & -11.7 & -30.0 & -35.7 & 4.5 & 18.6 & 1.6 & 3.8 \\
\hline East & -30.4 & -6.2 & -43.4 & -38.7 & -51.0 & -11.8 & -31.7 & -30.4 \\
\hline Central & -8.4 & 18.7 & -50.8 & 5.3 & -11.5 & -50.2 & -49.4 & -20.9 \\
\hline South & -13.3 & -7.8 & -17.0 & -11.5 & -2.4 & 1.2 & 11.9 & -5.6 \\
\hline
\end{tabular}


(a)

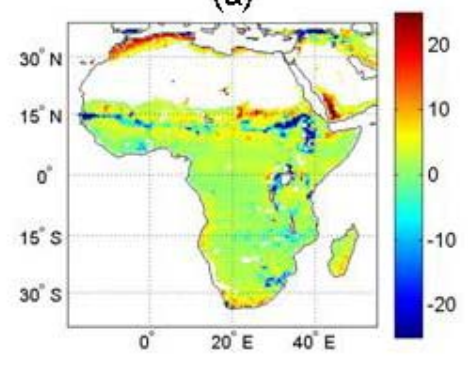

(c)

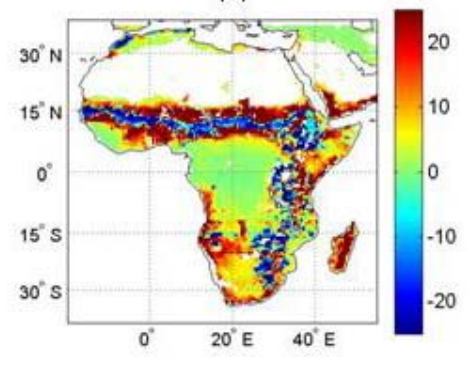

(e)

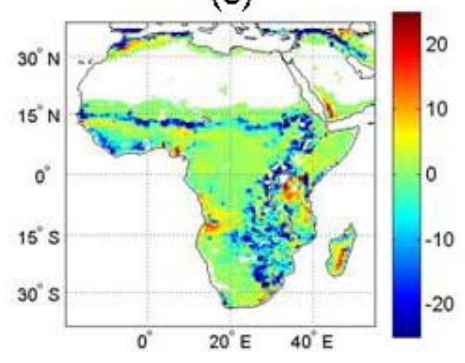

(b)

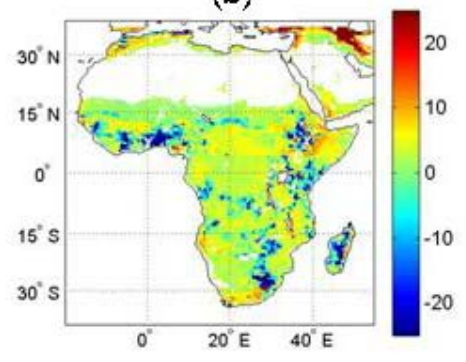

(d)

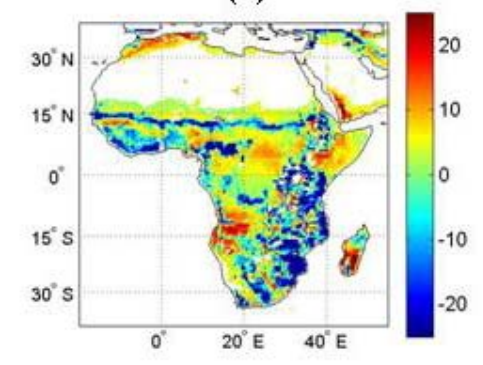

(f)

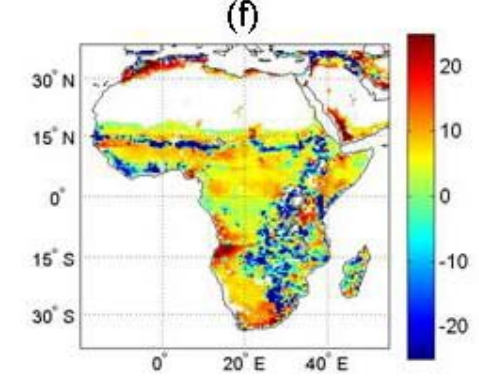

\section{Figure 1: Geographic distribution of residuals for the cropland models}

Cropland models were estimated from MODIS (a), GLCF (b), GLC2K (c), ORNL (d), SAGE (e) and IFPRI (f) land cover maps. Positive residuals (overestimates) are shown in yellow-tored colors, and negative residuals (underestimates) are shown in green-to-blue colors (in percent cropland share). The models tend to underpredict the actual cropland share in areas with higher density of agricultural land, e.g. eastern Africa and Ethiopia, and overpredict in sparser agro-ecosystems such as the Sahel and the Horn of Africa. 

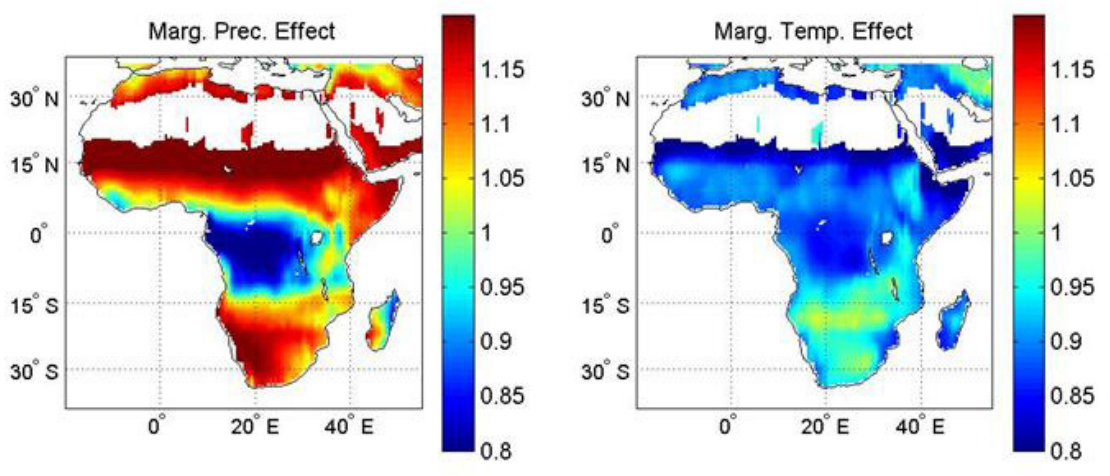

Figure 2: Geographic patterns of cropland sensitivity to precipitation and temperature

Cumulative marginal effects for precipitation and temperature across all seasons (winter, spring, summer, fall) were evaluated at long-term (1961-2000) mean conditions for each location (grid cell). Changes in the odds ratio per unit change in seasonal precipitation $(10 \mathrm{~mm} / \mathrm{month})$ and temperature $\left({ }^{\circ} \mathrm{C}\right)$ are averaged across all six cropland models. Positive marginal effects $(\mathrm{Q}>1)$ are shown in yellow-to-red colors, and negative marginal effects $(\mathrm{Q}$ $<1$ ) in green-to-blue colors. For instance, $\mathrm{Q}=1.1$ indicates that the odds of land being used for cropping increases by $10 \%$ if the long-term mean monthly precipitation increases by $10 \mathrm{~mm}(120 \mathrm{~mm} /$ year). Increases in precipitation have a positive effect on croplands (left) in subtropical regions $\left(10-20^{\circ} \mathrm{N}\right.$ and $\left.20-30^{\circ} \mathrm{S}\right)$ whereas they are neutral or negative in tropical regions. For temperature, increases in seasonal temperature have negative effects for most of the African continent, with the exception of mild positive effects in parts of southern Africa. 

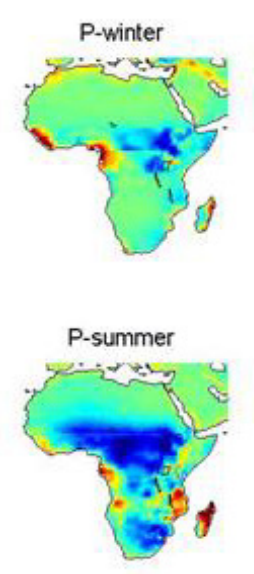
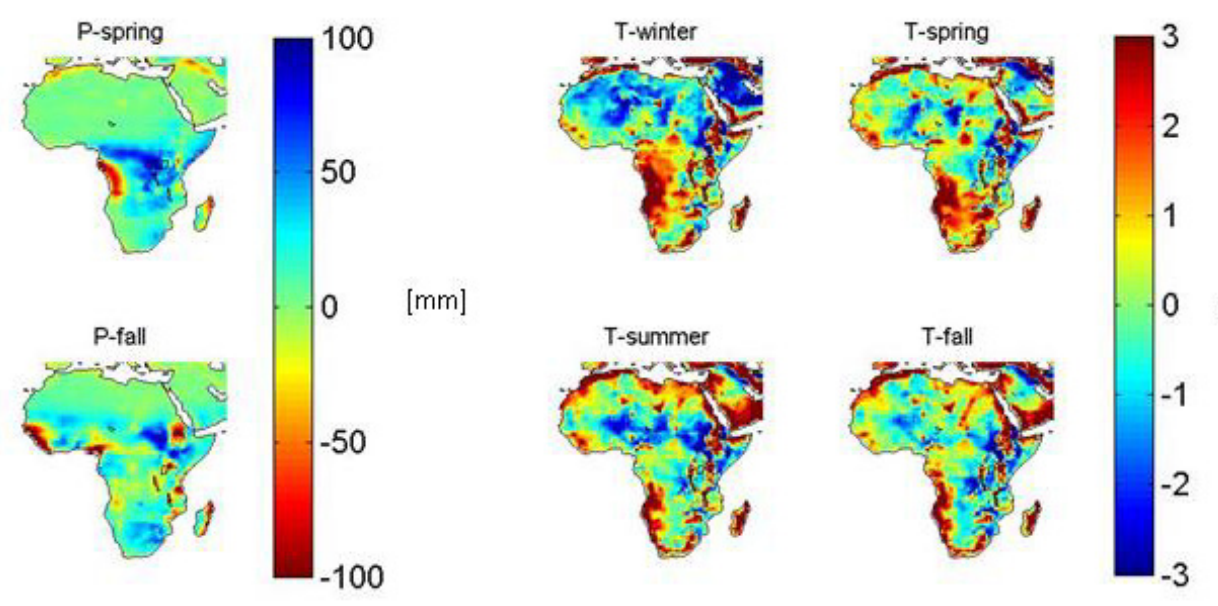

\section{Figure 3: Climate model projections of changes in precipitation and temperature}

Projected changes in precipitation $(\mathrm{mm})$ and temperature $\left({ }^{\circ} \mathrm{C}\right)$ for each season (winter, spring, summer, fall) are derived from an ensemble of transient climate projections from seven AOGCM (2010-2039 long-term mean). Wetter conditions (blue colors, 4 panels on left) are likely to be more prevalent in the semi-arid regions of eastern Africa and the Sahel in particular during the warmest seasons (spring, summer), whereas the coastal regions are characterized by drier conditions (red colors). Warming (4 panels on right) is strongest in coastal regions (red colors) during the winter and spring, and cooling (blue colors) is projected to occur in areas of eastern Africa and the Sahel and coincides with the positive projected changes in precipitation. 

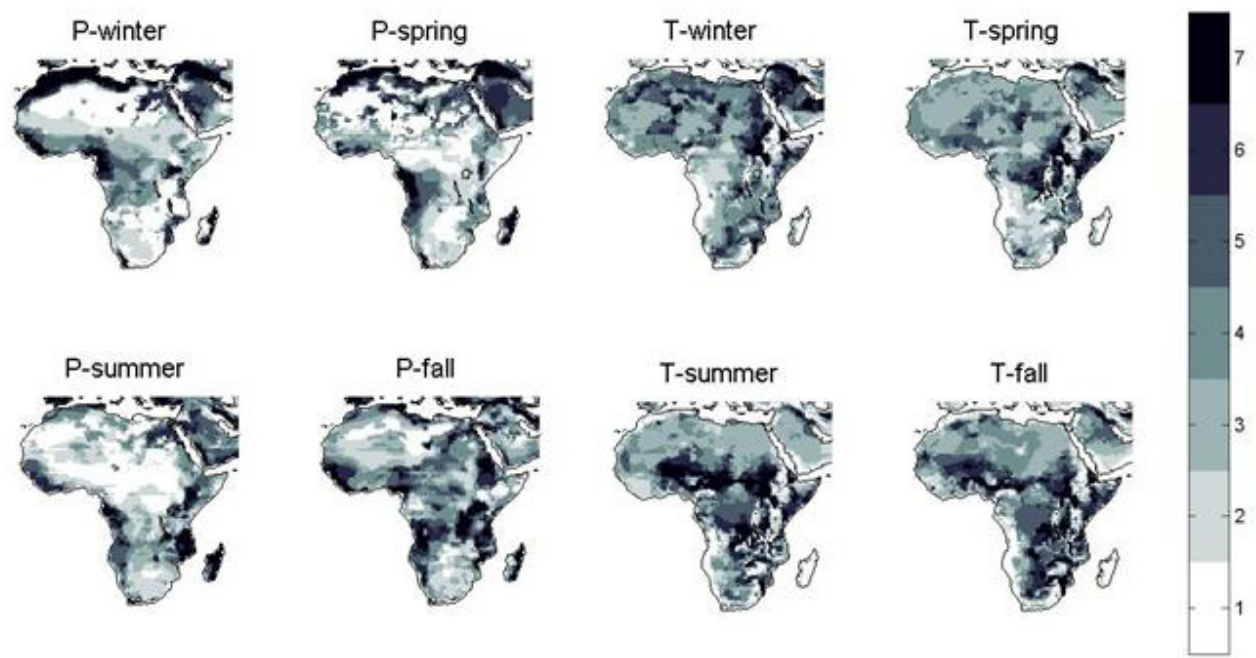

\section{Figure 4: Agreement of climate models on changes in seasonal climate}

The agreement among seven AOGCMs on the direction of precipitation and temperature change for future long-term (2010-2039) average conditions was determined for each grid cell. For precipitation (left panels), darker colors indicate higher agreement on future conditions being drier relative to the 1961-2000 baseline (i.e. white and light grey areas indicate agreement on wetter conditions). For temperatures (right panels), darker colors indicate model agreement on cooler-than-baseline conditions (lighter colors reflect agreement on warmer seasonal temperatures). Grey areas, i.e. agreement among 3-4 models out of seven, are therefore indicative of a relatively high degree of uncertainty about future climate changes. Overall there is high agreement on semi-arid regions becoming wetter (in particular during spring and summer) and tropical coastal regions becoming drier. There is also high agreement among models on large areas of western, central and southern Africa becoming warmer (mostly during winter and spring) and large parts of the eastern part of the continent and the subtropical areas becoming cooler. 

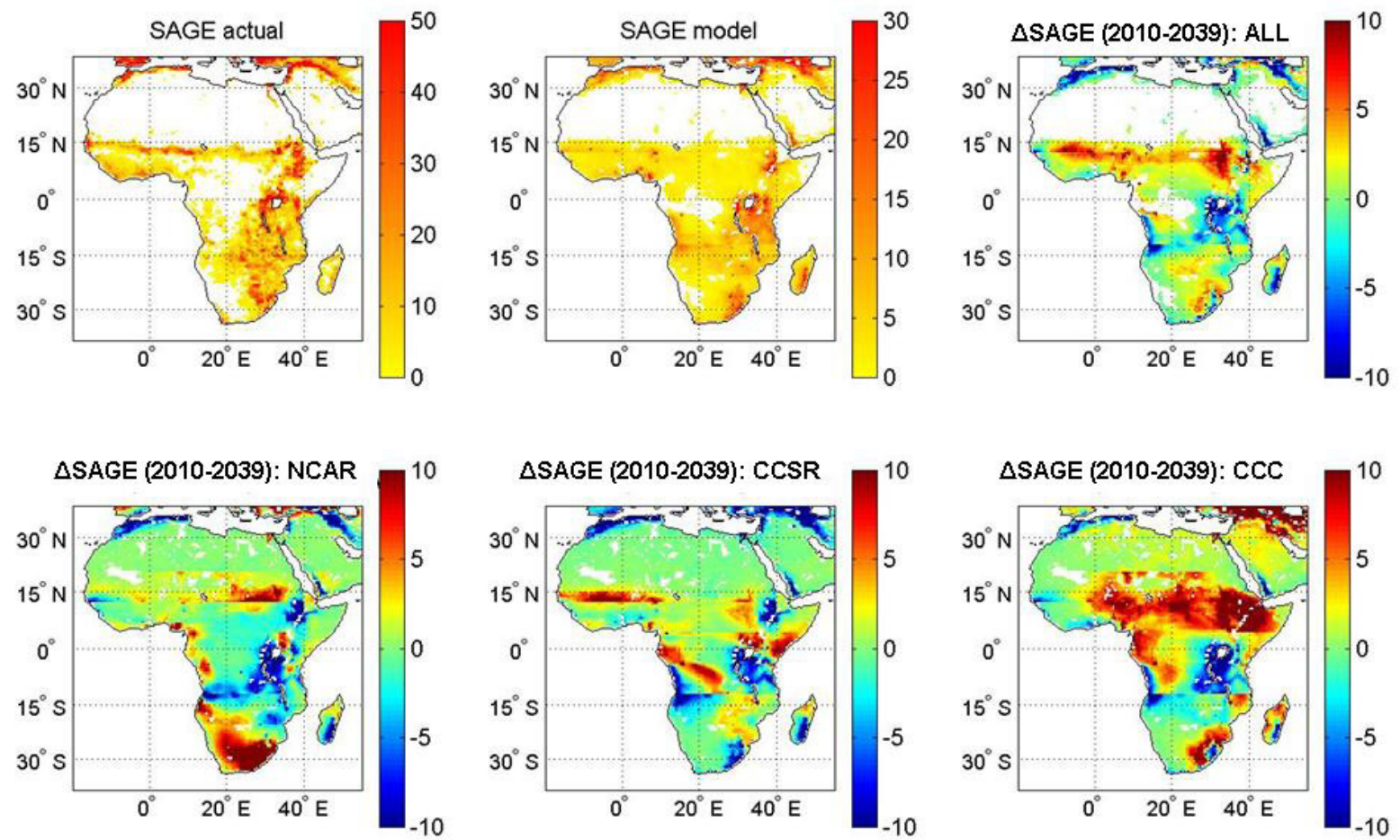

Figure 5: Changes in cropland share predicted by climate models

Long-term (2010-2039) changes in cropland share (in percent) arising from changes in seasonal temperature and precipitation patterns are estimated from an ensemble of seven AOGCMs (top right panel). Cropland sensitivities are based on the SAGE cropland model (for summary of other cropland models see Table 4). Actual (current) and modeled distribution of cropland share (percent) based on the SAGE data are shown in the left and center panels, respectively. Cropland share in subtropical regions $\left(10-15^{\circ} \mathrm{N}\right.$ and $\left.15-30^{\circ} \mathrm{S}\right)$ is expected to increase, whereas croplands in tropical regions are expected to decrease, in particular in tropical eastern Africa (Great Lakes region). 



\section{Policy Research Working Paper Series}

Title

WPS4263 HIVIAIDS and Social Capital in a Cross-Section of Countries

WPS4264 Financing of the Private Sector in Mexico, 2000-05: Evolution, Composition, and Determinants

WPS4265 The Structure of Import Tariffs in the Russian Federation: 2001-05

WPS4266 The Economic Community of West African States: Fiscal Revenue Implications of the Prospective Economic Partnership Agreement with the European Union

WPS4267 Financial Intermediation in the Pre-Consolicated Banking Sector in Nigeria

WPS4268 Power to the People: Evidence from a Randomized Field Experiment of a Community-Based Monitoring Project in Uganda

WPS4269 Shadow Sovereign Ratings for Unrated Developing Countries

WPS4270 Jump-Starting Self-Employment? Evidence among Welfare Participants in Argentina

WPS4271 Construction, Corruption, and Developing Countries

WPS4272 Migration, Remittances, Poverty, and Human Capital: Conceptual and Empirical Challenges

WPS4273 Rules of Origin and the Web of East Asian Free Trade Agreements

WPS4274 Are Labor Regulations Driving Computer Usage in India's Retail Stores?

WPS4275 Can Foreign Lobbying Enhance Development? The Case of Tourism in the Caribbean

WPS4276 Human Capital, Trade Liberalization, and Income Risk

WPS4277 Climate Change Adaptation in Africa: A Microeconomic Analysis of Livestock Choice

WPS4278 Endogenous Irrigation: The Impact of Climate Change on Farmers in Africa

WPS4279 The Impact of Climate Change on Livestock Management in Africa: A Structural Ricardian Analysis
Author

Date

\section{Contact for paper}

Antonio C. David

June 2007

A. David

82842

Constantinos Stephanou

June 2007

S. Coca

Emanuel Salinas Muñoz

37474

Oleksandr Shepotylo

June 2007

P. Flewitt 32724

Simplice G. Zouhon-Bi June 2007

S. Zouhon-Bi Lynge Nielsen 82929

Heiko Hesse

June 2007

G. Johnson 34436

Martina Björkman

June 2007

I. Hafiz

Jakob Svensson

Dilip Ratha

June 2007

N. Aliyeva

80524

Sanket Mohapatra

Rita Almeida

June 2007

A. Bonfield 31248

Charles Kenny

June 2007

C. Kenny 33540

David McKenzie

July 2007

M. Sasin

36877

Miriam Manchin

July 2007

Annette O. Pelkmans-Balaoing

Mohammad Amin

July 2007

L. Yeargin

81553

S. Narsiah 88768

Kishore Gawande

July 2007

V. Cornago

William Maloney

Gabriel V. Montes Rojas

Tom Krebs

July 2007

V. Cornago

Pravin Krishna

William Maloney

Sungno Niggol Seo

July 2007

P. Kokila

Robert Mendelsohn

Pradeep Kurukulasuriya July 2007

Robert Mendelsohn

Sungno Niggol Seo

Robert Mendelsohn
33716

P. Kokila

33716

July 2007

P. Kokila 33716 
Policy Research Working Paper Series

Title

WPS4280 Governance Matters VI: Aggregate and Individual Governance: Indicators, 1996-2006

WPS4281 Credit Growth In Emerging Europe: A Cause For Stability Concerns?

WPS4282 Are Cash Transfers Made to Women Spent Like Other Sources of Income

WPS4283 Innovation Shortfalls

WPS4284 Customer Market Power and the Provision of Trade Credit: Evidence from Eastern Europe and Central Asia

WPS4285 Poverty Analysis Using An International Cross-Country Demand System

WPS4286 Institutional Effects as Determinants of Learning Outcomes: Exploring State Variations in Mexico

WPS4287 A Cross-Country Analysis of Public Debt Management Strategies

WPS4288 Actual Crop Water Use in Project Countries A Synthesis at the Regional Level
Author

Date

Daniel Kaufmann

Aart Kraay

Massimo Mastruzzi

Sophie Sirtaine

Ilias Skamnelos

Norbert Schady

José Rosero

William Maloney

Andrés Rodríguez-Clare

Neeltje Van Horen

July 2007

. A. L. Cranfield

Paul V. Preckel

Thomas W. Hertel

Jesús Álvarez

Vicente García Moreno

Harry Anthony Patrinos

Martin Meleckyy

Robina Wahaj

Florent Maraux

Giovanni Munoz

July 2007

July 2007

July 2007

July 2007

July 2007

July 2007

July 2007

July 2007

\section{Contact for paper}

R. Bonfield 31248

S. Sirtaine 87006

I. Hafiz 37851

V. Cornago 84039

M. Gamboa 34847

P. Flewitt 32724

S. Baksh 31085

M. Rosenquist 82602

P. Kokila

33716 